OPEN ACCESS

Edited by:

Fidelis A. Emuze,

Central University of Technology,

South Africa

Reviewed by:

Hongling Guo,

Tsinghua University, China

Oriol Pons Valladares,

Universitat Politecnica de Catalunya,

Spain

*Correspondence:

Mark Swallow

mswallow@/cb.ac.uk

Sam Zulu

s.zulu@leedsbeckett.ac.uk

Specialty section:

This article was submitted to

Sustainable Design and Construction,

a section of the journal

Frontiers in Built Environment

Received: 10 September 2018

Accepted: 19 December 2018

Published: 11 January 2019

Citation:

Swallow M and Zulu S (2019) Benefits and Barriers to the Adoption of $4 D$ Modeling for Site Health and Safety

Management.

Front. Built Environ. 4:86. doi: 10.3389/fbuil.2018.00086

\section{Benefits and Barriers to the Adoption of 4D Modeling for Site Health and Safety Management}

\author{
Mark Swallow ${ }^{1 *}$ and Sam Zulu ${ }^{2 *}$ \\ ${ }^{1}$ Higher Education Construction Management, Leeds College of Building, Leeds, United Kingdom, ${ }^{2}$ School of the Built \\ Environment, Leeds Beckett University, Leeds, United Kingdom
}

The use of Building Information Modeling processes and supporting technology in the construction industry continues to grow. Its application to various project processes including management of health and safety is acknowledged. The aim of this study was to investigate the current perception of industry professionals regarding the benefits and barriers of the adoption of 4D modeling for management of construction site safety. This is in light of the BIM level 2 framework document PAS1192-6:2018, which promotes the integration of $4 \mathrm{D}$ modeling for safer design and construction. The paper reports findings from a questionnaire survey of 141 construction industry professionals. The analysis of data took into account the level of seniority of the participants. The study indicated that $70 \%$ of directors/managers and $74 \%$ of professionals are aware of $4 \mathrm{D}$. This awareness, however, is not reflected in the current adoption rate as an average of $31.2 \%$ of participants had adopted the 4D modeling at their workplace. The study identifies that the perceived primary purpose of $4 \mathrm{D}$ is not for health and safety management, although a need for this purpose is evident. The main perceived benefits of $4 \mathrm{D}$ were adding value through visualization and clearer communication of project outputs, issues which have positive effects on health and safety management including site planning and logistics. The findings also showed that seniority can influence the perception of barriers to $4 D$ modeling adoption. Such barriers include the cost of training, time to implement and underlining cultural issues. The study recommends an increase in further education and training in BIM and health and safety management. Further evidence-based exploratory studies and promotion of $4 \mathrm{D}$ modeling to demonstrate the value of $4 \mathrm{D}$ modeling for construction site safety would also be useful as a platform to encourage the uptake of 4D modeling for construction site safety.

Keywords: construction, BIM, 4D modeling, health and safety, PAS1192-6:2018

\section{INTRODUCTION}

The construction industry is a fast-paced, project-based industry (Kumar, 2015) involving highrisk activities (Fung et al., 2010). Health and safety management is, therefore, a key aspect to consider throughout a project (Lacey, 2015) and should begin at the early stages. However, delivery of high-risk activities and complex site logistics during an often strict and rigid timeframe can be difficult to predict, therefore challenging to effectively plan. This unpredictability can 
lead to extensive co-ordination time, costs (Smith et al., 2009), increased safety risk and result in potential miscommunication of expectations or outcomes between the project teams. Early accurate planning of site activities can allow the team to make the most effective decisions (Abdulkadir and Godfaurd, 2015) for the project, which would assists in the reduction of cost, time, aborted works and increased safety. To achieve these specific project outcomes and reduced risk to those carrying out (or affected by) the construction activities, a clear understanding of the outcomes and methodology is required.

The construction industry remains a high-risk industry in the UK, with the Health and Safety Executive (2018) recording 38 fatalities in the construction industry in 2017/18. With an emphasis on legislative requirements, such as that required under the Construction (Design Management) regulations (Health and Safety Executive, 2015), and the moral and financial impacts of poor safety management (Hughes and Ferrett, 2016), the industry continues to require improvement. The nature of construction is, however, a continually developing environment, which often involves numerous coexisting high-risk physical activities. These activities can often be temporary, with exposure to natural elements, involving major plant and equipment, creating difficult logistical interfaces. With this in mind, the reasons behind these current statistics could be due to its nature or traced to other core issues, linked to a historical poor history and culture toward health and safety (Lacey, 2015).

The construction industry has however made progress in improving standards in managing health and safety. This in part has been influenced by the findings of many reports such as those by Latham (1994) and Egan (1998), who both criticized the industries approach and attitudes toward many aspects, including site safety conditions and workflows. In addition, Egan (1998) identified the slow adoption of digital software to support effective processes and identified these as clear cultural issues.

According to Abdulkadir and Godfaurd (2015), most of the recommendations proposed by the Egan (1998) have been implemented by the construction industry, indeed in recent years, the industry has begun to embrace digital technologies to improve its processes. Although the industry is still criticized for its lack of innovation (Gledson, 2016) a clear push for digital processes is evident, with a UK government mandate for BIM level 2 in place since 2016. The process involves collaborative approaches, structured information, and digital software. In addition, with a need to improve safety within the construction industry, the PAS1192-6:2018 document has been published by the British Standards Institution (BSI). This standard forms as part of the BIM level 2 framework and focuses on collaborative sharing and use of structured health and safety information. Within this standard, the encouragement to adopt digital technologies including the use of $4 \mathrm{D}$ is clear by stating, "Each participant shall adopt the use of $3 \mathrm{D}$ or $4 \mathrm{D}$ construction sequencing model(s) to support the development and visualization of safe methods of access and working" (British Standards Institution, 2018, p. 11).

Adding the dimension of "time," 4D has been an area of active research (Tanyer and Aouad, 2005) and is regarded as a useful addition to project management (Koo and Fisher, 2000), resulting in a range of software emerging over recent decades including design and management applications. 4D software has been developed to allow the project team to manage structured schedule data and create a further visualization of the project throughout its construction. For example, this approach gives the project team opportunities to assess and agree its sequence as confirmation that the plan will execute correctly.

Whilst there is a significant volume of research into BIM and $4 \mathrm{D}$ modeling for safety management, this is a developing and evolving field (Migilinskasa et al., 2013), both in industry and academia with few studies analyzing the industries perception of these processes. Due to the incremental nature of BIM adoption (NBS, 2017) and the push to use 4D modeling for safety planning on construction projects, this study aims to contribute to this field by investigating the current perception of industry professionals of the benefits and barriers to the adoption of $4 \mathrm{D}$ modeling for management of construction site safety. While most studies have focused on the general application of $4 \mathrm{D}$ modeling for H\&S management, this study focused on the application of the technology and process at a construction site management level.

\section{MATERIALS AND METHODS}

\section{Background}

\section{Health and Safety in the Construction Industry}

Within any working environment, safety is a factor among many others, which must be considered. The widespread implications of poor safety in the workplace can result in loss of life and or serious damage (Lacey, 2015); thus having various effects on the project, companies and individuals involved. For this reason, the importance of health and safety within the construction industry is extremely high. The construction industry is the largest in the UK, employing around $10 \%$ of the working population (Hughes and Ferrett, 2016) and is one of the highest risk industries. According to Pinto et al. (2011) the construction industry is plagued by risky situations and poor site conditions. With an industry focused on performance outcomes, (particularly cost and time constraints) effective planning to enable the most effective methods is needed to reduce these site risks.

Statistical data from the Health and Safety Executive (HSE) does indicate a gradual decrease in both fatalities and reportable injuries within the construction industry over recent years. However, with a $27 \%$ increase in fatalities from 2016/2017 to 2017/2018 this would suggest there are still large improvements to be made within the industry. The main causes of these fatalities are collisions, workers struck by moving vehicles/objects and working at height (Health and Safety Executive, 2017, 2018).

The Construction (Design and Management) Regulations (CDM), revised in 2015 have been designed specifically for the construction industry and require duty holders to identify, eliminate or control foreseeable health and safety risk throughout and apply the principles of prevention (Health and Safety Executive, 2015). The planning, preparation and management of health and safety should be considered and executed at all stages of a projects life cycle (Zhou et al., 2013; Lacey, 2015) from strategic definition through to the use and demolition of an asset (RIBA, 2015). The project team's development of 
the information during the pre-construction phase is driven by key project outcomes, including the health and safety of those constructing the asset and of the end users. This requires detailed planning and coordination (Health and Safety Executive, 2015) during the preparation, design and construction stages of the project (RIBA stages 1-5). The decisions made during these stages are highly influential in how the asset is to be constructed, used and maintained. However, it is those stages leading up to construction and indeed the construction stage itself, which contains the physical risk (Abdulkadir and Godfaurd, 2015). Due to this, the methodology choices should be tested and confirmed to ensure a safe working, operational environment (Mordue and Finch, 2014).

The Health and Safety Executive (2015) suggest it is essential that site activities are effectively pre-planned to enable the works to be carried as far as reasonably practicable without risk. The CDM Regulations (2015) states the requirements for managing all aspects of health and safety during the continually evolving and changing construction phase, requiring the Principal Contractor to

\section{'...plan, manage and monitor the construction phase and coordinate matters relating to health and safety during the construction phase to ensure that, so far as is reasonably practicable, construction work is carried out without risks to health or safety' (Health and Safety Executive, 2015, p. 36).}

The development and enforcement of the CDM regulations 2015 have an influence on the planning process, ensuring that pre-construction and construction information is exchanged collaboratively between the design and construction teams (Health and Safety Executive, 2015).

\section{Challenges of Managing Health and Safety}

Due to the importance of health and safety in construction, it is key that this is embedded within the industry (Lingard and Rowlinson, 2005), from definition and design to on-site activities. The management of health and safety can, however, face a number of challenges, including:

- Cultural attitudes toward safety (Lacey, 2015).

- Financial support for training, developed processes, and suitable equipment.

- Limited resources.

- Human behavior (Dester and Blockley, 1995).

- Project timescales (Faridi and El-Sayegh, 2007).

Dester and Blockley (1995) suggests cultural and human behavioral factors are the core reasons for a historically poor record of safety in the construction industry; with cost, timescales, and training often having an influence on this behavior. The construction industry is also a competitive industry, therefore, understanding the project and its methodology is key to ensuring that the correct funds and resources are allocated to provide an adequate working environment. If the project timescales in tender and construction are short and/or limited information is provided, this can reduce the likelihood of correct decisions being made regarding safe methodology. Allowing adequate time to ensure that safety can be fully considered and planned is therefore essential (Faridi and El-Sayegh, 2007).

Lingard and Holmes (2010) proposes that the industry has a challenge in making decisions, which are equitable to all members of the process. According to Hughes and Ferrett (2016), a positive, collaborative safety culture should be embedded within the company ethos, through investment in people, processes and equipment, clear safety policies, communication, leadership and commitment to health and safety. The issues regarding collaboration can be assisted in the use of structured processes, techniques, and advanced digital technologies, as stated in PAS1192-6:2018 (British Standards Institution, 2018).

\section{Application of 4D to Health and Safety Management}

Construction projects often include bespoke structures, regularly involving complex designs, interfaces and logistics, involving numerous team members and project stakeholders. A clear understanding of project deliverables, timescales and methodology is key to safe design and construction of projects. In order to achieve these outcomes, with ever increasing project complexities (Abdulkadir and Godfaurd, 2015), planners would design construction schedules, linking project activities to timescales and duration. Ahmed et al. (2014) however, suggests that poor interpretation of these schedules often leads to various conflicts and errors throughout the duration of the project. Azhar and Bahringer (2013, p. 1) state that "the link between planning for safety and work task execution is often weak" proposing that BIM technologies can further improve safety on site by a collaborative approach to construction planning and in addition, providing advanced visualization methods to illustrate site safety plans and procedures.

A 4D model involves the synchronization of graphical model components with schedule data (Zhang and Li, 2010). This creates a visual construction sequencing model (Hardin and McCool, 2015). The process allows the schedule information, once an isolated process to be visualized. This can allow the project team to assess the logic and sequence of the proposed plan and ascertain if this is possible or most effective. This provides opportunities for alternative options to be explored and to select optimum methodologies. The $4 \mathrm{D}$ model can also be used for continuous visualization and management as potential safety risks evolve. Zhou et al. (2013) argue that the proposed approach can be a collaborative tool in which detection of safety risks prior and throughout the construction process can be assessed and preventative measures evaluated in order to avoid accidents.

According to Zhang and Li (2010), a virtual representation of the construction process (virtual construction) can simulate the activities involved during construction using virtual simulation technologies or virtual reality. Virtual construction has a number of key benefits, these include identifying potential issues, risks and problems that may occur with the real construction process ahead of time to allow preventative measures to be planned. 4D simulations can be generated which could be focused on the safety procedures. These simulations can identify methodology, temporary safety elements and can highlight areas of concerns within the project (Azhar et al., 2012). A number of rulebased systems (Zhou et al., 2013) have been developed. For example, Vacharapoom and Sdhabhon (2010) discussed systems 
designed to automatically detect high-risk site activities and indicates necessary safety measures. The control measures are then incorporated into the schedule and further visualized on the $4 \mathrm{D}$ model.

The further potential for $4 \mathrm{D}$ modeling has been identified in the literature, from $4 \mathrm{D}$ virtual reality to live tracking applications. According to Saeedfar (2017), the further utilization of the model data and geometry allows for "Live safety tracking." This process involves the live data within the model to be used for tracking objects, activities and operatives within the site. The potential for this includes levels of dust and noise as well as incorporating monitoring using sensors and tag systems.

\section{Benefits of 4D Modeling for Construction Health and Safety Management}

A number of general benefits for use of $4 \mathrm{D}$ modeling have been identified in literature. These include increase collaboration (Mahalingam et al., 2010) reduce risk, error (Dawood, 2010), increase communication (Azhar et al., 2012), and identify issues in sequencing (Zhou, 2009) by having the ability to rehearse project activities and demonstrate how the plan would play in a "virtual world." According to the British Standards Institution (2018), digital information modeling software with 4D capability enhances the ability to foresee hazards and risk. Azhar et al. (2012) suggests that a collaboratively created, virtually simulated environment is to be a revolutionary development, further stating

\begin{abstract}
'The utilization of BIM technology can result in improved occupational safety by connecting the safety issues more closely to construction planning, providing more illustrative site layout and safety plans, providing methods for managing and visualizing upto-date plans and site status information, as well as by supporting safety communication in various situations within the construction industry' (Azhar et al., 2012, p. 83).
\end{abstract}

$4 \mathrm{D}$ modeling is also seen to be a useful tool to aid safety and project planning on construction projects (Kassem et al., 2012). This view is shared by Barnes and Davies (2015) who suggests that $4 \mathrm{D}$ scheduling and simulation provides a platform for improved planning and management of construction activities.

Gledson (2016) proposes that the key benefits of 4D are in the reduction of uncertainty in the planning process. Mordue and Finch (2014) imply that the use of digital software and collaborative approaches enables a further enhancement in forecasting and planning in regards to site safety. As BIM has been acknowledged by the Health and Safety Executive, creating synergy between BIM and health and safety management is the move forward. The value in adopting this process to management of health and safety is widely acknowledged. For example, according to Cousins (2016), the use of 4D to rehearse activities of the proposed build in a virtual environment could be a key to allow accurate planning of site safety as it provides a platform to identify potential hazard, and modalities for trying potential solutions to mitigate the risks in the pre-construction stage.

Further research carried out by Gledson and Greenwood (2016) assessed the adoption of 4D BIM in the UK. The results indicated a significant relationship between the size of a company and the adoption of BIM as well as a link between the use of $4 \mathrm{D}$ and the companies' maturity. The research showed that $52.9 \%$ of participants surveyed, worked for companies using $4 \mathrm{D}$ on current projects and almost $70 \%$ of those surveyed believed that $4 \mathrm{D}$ could "add value to their business." The study identified that key benefits of $4 \mathrm{D}$ are related to "handling and communicating information" as opposed to managing timescales.

As stated within PAS1192-6:2018, the use of 4D modeling provides a number of benefits in regards to health and safety management. The BIM level 2 framework standard aims to support the integration of health and safety data within information management processes, stating

'A $4 D$ animation can be used to review, assess and communicate construction options, hazards and risk. A 4D animation of difficult construction sequences is more easily understood by those who have to take responsibility and accountability of risk mitigation, control and management' (British Standards Institution, 2018, p. 5).

According to Sulankivi (2010), 4D should be a central focus in the management of site health and safety. Although the research highlighted the potential for challenges and limitations, key benefits to the process were also identified. These benefits include the integration of safety within the planning process. Utilizing 4D BIM supporting software to communicate site layout plans, allowing accurate co-ordination for safety risk analysis. The use of this structured process and technology can be used for accurate visualization of site safety arrangements including plant, welfare and safe zones and allows for clearer communication between the project team.

Mahalingam et al. (2010) proposes that $4 \mathrm{D}$ is to be particularly useful in assessing the constructability of work methodology, increasing visualization, the ability to detect clashes and providing simulations which assist in planning and further analysis of project methodology. Analysis of data from this study concluded

' $4 D C A D$ is likely to be most beneficial in the project shaping
or planning stage and in the construction stage. In the project
shaping stage, $4 D$ CAD is likely to be particularly useful in
communicating construction plans and processes to clients, while
during the construction phase, $4 D$ CAD is likely to be particularly
useful in comparing the constructability of work methods visually
in order to detect conflicts or clashes, and as a visual tool for
contractors, clients, subcontractors and vendors to review and plan
project progress' (Mahalingam et al., 2010, p. 148).

Abdulkadir and Godfaurd (2015) linked the use of $4 \mathrm{D}$ for specific health and safety purposes, stating that the technology is critical to the success of a project. This can be achieved by effective control of the programme and reducing risk by "time-controlled realistic simulation." The use of this digital construction approach is not only useful as a tool to increasing collaboration and further value in construction (Barnes and Davies, 2015) but also to reduce project risk (Pittard and Sell, 2016). Rwamamara et al. (2010) also argue that $4 \mathrm{D}$ has potential in regards to detailed visualization and communication of construction information. The identification of health and safety 
TABLE 1 | Summary of the benefits of 4D in relation to health and safety management.

\begin{tabular}{|c|c|}
\hline Benefit & References \\
\hline Reduce safety risk & $\begin{array}{l}\text { Dawood, 2010; Rwamamara et al., 2010; } \\
\text { Vacharapoom and Sdhabhon, 2010; Azhar } \\
\text { et al., 2012; Azhar and Bahringer, 2013; Zhou } \\
\text { et al., 2013; Mordue and Finch, 2014; } \\
\text { Abdulkadir and Godfaurd, 2015; Pittard and } \\
\text { Sell, } 2016\end{array}$ \\
\hline Ability to foresee hazards & $\begin{array}{l}\text { Rwamamara et al., 2010; Vacharapoom and } \\
\text { Sdhabhon, 2010; Zhang and Li, 2010; Azhar } \\
\text { et al., 2012; Azhar and Bahringer, 2013; Zhou } \\
\text { et al., 2013; Mordue and Finch, 2014; } \\
\text { Abdulkadir and Godfaurd, 2015; Cousins, } \\
\text { 2016; British Standards Institution, } 2018\end{array}$ \\
\hline Improved project planning & $\begin{array}{l}\text { Zhou, 2009; Mahalingam et al., 2010; } \\
\text { Sulankivi, 2010; Vacharapoom and Sdhabhon, } \\
\text { 2010; Zhang and Li, 2010; Azhar et al., 2012; } \\
\text { Kassem et al., 2012; Azhar and Bahringer, } \\
\text { 2013; Zhou et al., 2013; Mordue and Finch, } \\
\text { 2014; Abdulkadir and Godfaurd, 2015; Barnes } \\
\text { and Davies, 2015; Gledson, } 2016\end{array}$ \\
\hline Improved communication & $\begin{array}{l}\text { Mahalingam et al., 2010; Rwamamara et al., } \\
\text { 2010; Azhar et al., 2012; Azhar and Bahringer, } \\
\text { 2013; Gledson and Greenwood, } 2016\end{array}$ \\
\hline Increased collaboration & $\begin{array}{l}\text { Mahalingam et al., 2010; Azhar et al., 2012; } \\
\text { Azhar and Bahringer, 2013; Zhou et al., 2013; } \\
\text { Mordue and Finch, 2014; Barnes and Davies, } \\
\text { 2015; Carson, } 2018\end{array}$ \\
\hline $\begin{array}{l}\text { Increased project } \\
\text { visualization }\end{array}$ & $\begin{array}{l}\text { Mahalingam et al., 2010; Rwamamara et al., } \\
\text { 2010; Vacharapoom and Sdhabhon, 2010; } \\
\text { Zhang and Li, 2010; Azhar et al., 2012; Azhar } \\
\text { and Bahringer, 2013; Zhou et al., } 2013\end{array}$ \\
\hline
\end{tabular}

risks (in specific regards to material movement and repetitive manual operations) during the design process can be a key advantage of $4 \mathrm{D}$ as well as clash detection and optimization of work sequences, which reduce workspace congestion can be further highlighted.

As demonstrated above, a number of benefits for use of $4 \mathrm{D}$ modeling are identified in the literature. Table $\mathbf{1}$ below provides a summary of these potential benefits.

\section{Barriers of 4D Within the Construction Industry}

According to Romigh et al. (2017), the implementation of $4 \mathrm{D}$ requires improvement within the construction industry. A qualitative study highlighted the role in which $4 \mathrm{D}$ has during the construction phase in regards to visualization and communication of the schedule data to improve site operations. The study utilized semi-structured interviews to collect data regarding $4 \mathrm{D}$ adoption and use, stating that $67 \%$ of those interviewed were familiar and a minority of $33 \%$ used $4 \mathrm{D}$ on their projects. The findings from these interviews also identified common perceptions of the interviewees, suggesting that the use of $4 \mathrm{D}$ is limited. The study also stated that some participants believed $4 \mathrm{D}$ was mainly used as a marketing tool and that most were not interested in the idea of updating a 4D model as opposed to a $2 \mathrm{D}$ schedule during projects which are constantly changing.
A concern which Zhou (2009) highlights is that 4D approaches are limited due to lack of a fully collaborative environment. 4D CAD approaches also provide a planning review mechanism as opposed to a platform for a novel integrated approach to construction planning. This called for the development of a virtual reality environment where collaborative working could take place in order to create a fully integrated and coordinated programme and simulated project. Highlighted further were the issues of technological limitations and human behavior within such a working environment.

The construction industry as a whole has shown to have a history of slow adoption of new processes and technologies in comparison to other major industries. It is also seen as "having a reputation for a being slow to change" (Chevin, 2018, p. 23). Latham (1994) highlighted the positive effects of digital information to enhance construction performance and effective decision making, a view also echoed by Egan (1998) who further discussed the need for digital exchanging of data but also emphasized a cultural change before using this technology. Hardin and McCool (2015) also suggested that those who misunderstand the principle that BIM is a "cultural shift in the mind set in the way construction management teams collaborate" would soon be irrelevant in the industry. With this in mind, it is clear that the use of software must be supported by a collaborative and innovative culture.

Within the BIM process, technology is used to enable effective design and collaboration. However, as Hardin and McCool (2015) suggests, BIM requires people, process, and technology; with the most difficult to manage to be people as this often requires a cultural and behavioral change. Egan (1998) proposed that this behavioral and cultural change must take place before the technology can fully be utilized. This may suggest that before the technology can truly assist in the management of health and safety, the behaviors of those involved and the process and procedures in which they work need to be in place to accept this technology. The introduction of technology alone without this behavioral/cultural change and effective processes in place would inevitably end in failure, as Egan (1998, p. 28) stated "to approach change by first sorting out the culture, then defining and improving processes and finally applying technology as a tool to support these cultural and process improvements." The changing of culture can be challenging as those who have worked in the same way may find it difficult to accept and adapt to new ways of work (Eynon, 2016). It is argued that this core challenge of human behavior "cannot be changed quickly" (Azhar and Bahringer, 2013).

According to Abdulkadir and Godfaurd (2015), the use of $4 \mathrm{D}$ may improve safety although the adoption of this technology within the construction industry is currently "partial and fragmented." They suggest that the use of BIM and these technologies are mainly confined within the design and planning stages with "very little of it being used in the construction phase in relation to H\&S through hazard perception" (Abdulkadir and Godfaurd, 2015, p. 42).

Further barriers to the process and technology include the current client experience and project team expertise within the industry to implement BIM level 2 and the use of these 
TABLE 2 | Summary of the barriers of 4D in relation to health and safety management.

\begin{tabular}{ll}
\hline Barrier & References \\
\hline $\begin{array}{l}\text { Industry culture and } \\
\text { resistance to change }\end{array}$ & Latham, 1994; Egan, 1998; Azhar and \\
& $\begin{array}{l}\text { Bahringer, 2013; Ahmed et al., 2014; Mordue } \\
\text { and Finch, 2014; Hardin and McCool, 2015; } \\
\text { Eynon, 2016; Chevin, 2018 }\end{array}$ \\
Zhou, 2009; Azhar and Bahringer, 2013; & Abdulkadir and Godfaurd, 2015 \\
Lack of collaboration & Egan, 1998; Zhou, 2009 \\
Lack of awareness of 4D & Kassem et al., 2012; Ahmed et al., 2014; \\
Abdulkadir and Godfaurd, 2015 \\
Kassem et al., 2012; Abdulkadir and Godfaurd, \\
2015; Romigh et al., 2017 \\
Zost of software and \\
2013; Carson, 2018 \\
Kesource & Kassem et al., 2012; Azhar and Bahringer, \\
Lack of experience & 2013; Ahmed et al., 2014 \\
Azhar and Bahringer, 2013; Lymath, 2014 & Ahmed et al., 2014; Lymath, 2014 \\
Cost of training & Zhang and Li, 2010; Migilinskasa et al., 2013 \\
Demand for 4D & \\
Effective hardware &
\end{tabular}

technologies effectively. As highlighted by Lymath (2014) barriers to the adoption of BIM processes and software include the cost to recruit, train, and the demand for BIM in the industry, particularly for smaller projects and companies. The issues surrounding the cost of software, training and expertise could be a major challenge for the industry in order to see the true value in its adoption. According to Migilinskasa et al. (2013), knowledge which $4 \mathrm{D}$ modeling software to implement and understanding its limitations including data exchange and effective hardware where also potential issues. Zhang and $\mathrm{Li}$ (2010) also argued that 4D modeling requires high hardware requirements and that weak $3 \mathrm{D}$ outputs result in poor use of this information.

A change in culture may involve education and training in regards to health and safety but also training in the processes and the integration of the company policy and company ethos, all supported by high-level management, and suitable financial backing. Once accepted and agreed, the most appropriate technology can be selected to enable the process and assist those working within it, to manage project information effectively (Mordue and Finch, 2014; Hardin and McCool, 2015). As Kassem et al. (2012) identifies, barriers to this process are not just of the use of the software its self but of the business and stakeholder awareness of its value, stating

'... non-technical barriers, such as the inefficiency to quantify the tangible benefits of BIM and $4 D$ and lack of awareness by stakeholders, especially the clients, are affecting widespread use of BIM and 4D more than the technical barriers' (Kassem et al., 2012, p. 9).

The use of $4 \mathrm{D}$ as standard practice in the construction industry may face a number of barriers as the value in these new processes must be clear. These processes require a financial investment in software, training, and company infrastructure. The decision of these investments is often made by the highest level of management, requiring a collaborative and forwardthinking culture (Eynon, 2016). Understanding the financial risk and cost-effectiveness also needs to be considered with such an investment. The size of the company, resources, and risk of individual projects may all be contributing factors in the adoption of these technologies. According to Mills (2017), the use of 4D modeling software (including immersive VR) is clearly justifiable on many projects due to risks on major sites being much greater than the costs of software and its implementation. For smaller scale projects, the project risk may not be to this magnitude. Carson (2018) suggests that the benefits of BIM processes and software may not be clear, but that the barriers to its use, such as available resources may be evident. However, the use of BIM is to make improvement and the benefits of the collaboration of project data and a clearer understanding of environmental and safety concerns can be achieved.

Ahmed et al. (2014) carried out research into the barriers to $4 \mathrm{D}$ adoption using a survey approach to target construction professionals in which 54 responded. The results of the survey identified a number of barriers to its adoption including the availability of professionals who hold relevant skills, knowledge and experience in BIM and $4 \mathrm{D}$ as well as a clear resistance to change. Key barriers also included an unclear return on investment from the use of BIM and 4D. According to Azhar and Bahringer (2013), the adoption of BIM technologies including that of $4 \mathrm{D}$ for safety management poses a number of barriers and challenges. The challenges include a lack of knowledge and technical issues (mainly linking to safety objects within software libraries) as well as the cost associated with the development of these models and simulations.

Table 2 below provides a summary of potential barriers to adoption of $4 \mathrm{D}$ modeling for managing construction site safety.

\section{METHODOLOGY}

The primary focus of this research was to investigate the current perception of industry professionals of the benefits and barriers to the adoption of $4 \mathrm{D}$ modeling for management of construction site safety A survey approach using questionnaires was adopted as the method of collecting data for the study. This enabled collection of data from a relatively larger sample than would be the case if other methods such as interviews were used. The use of questionnaires to gather perception data is a common approach used in related studies, such as Gledson and Greenwood (2016) and Kassem et al. (2012). The questionnaire design was informed by issues identified in the literature as provided in the previous section.

In order to collect the data, a mixture of convenience and purposive sampling methods were used to assist in achieving a relatively high response rate (Bryman and Bell, 2007). The sampling approach targeted participants based on accessibility, and willingness but also targeted specific participants with particular characteristics (Etikan et al., 2016) based on their knowledge and experience (Bernard, 2002) and who are wellinformed in the subject (Cresswell and Plano Clark, 2011). In addition, the sampling method was selected in order to target a range of participants who hold either a director/management 
TABLE 3 | Sample demography (sector).

\begin{tabular}{lcc}
\hline Industry Sector & Number of participants & Percentage (\%) \\
\hline Construction & 76 & 54 \\
Civil infrastructure & 21 & 15 \\
Building services & 36 & 26 \\
Manufacturing & 8 & 5 \\
\hline Total & 141 & 100 \\
\hline
\end{tabular}

TABLE 4 | Participants level of seniority within their organization.

\begin{tabular}{lcc}
\hline Role & Number of participants & Percentage (\%) \\
\hline Director/Manager & 20 & 14 \\
Professional & 121 & 86 \\
\hline Total participants & 141 & 100 \\
\hline
\end{tabular}

or a professional position within the industry. The sample for the study consisted of managers and professionals within various sectors of the industry in order to receive data from the wider construction industry. Table 3 shows the sample demographic data including participants sectors, while Table 4 identifies participant seniority. A total of 141 participants completed the questionnaire, 20 who held direct/manager positions and 121 who held professional roles within the industry.

\section{RESULTS}

\section{BIM Level 2 Adoption}

The premise of the arguments in this paper is that as BIM adoption and practices develop further, the use of $4 \mathrm{D}$ modeling will be seen as an integral part of digital technology practices for the construction industry as advocated by the PAS11926:2018 document. The adoption of BIM level 2 is therefore seen as a key driver in the use of collaborative processes and digital software. Participants were therefore asked to identify their company's current implementation. The data in Table 5 indicates a low uptake of BIM level 2 being used in all projects (5.9\%). When the level of seniority is considered, the differences between the two groups are evident. For example, none $(0 \%)$ of the directors/managers indicated that BIM is used on all projects roles responded $0 \%$ in the field. The data, however, shows a $64.5 \%$ adoption of BIM level 2 (whether this is the on the majority or minority of projects) and $23.4 \%$ not currently adopting BIM level 2. The data suggests that the industry is adopting BIM processes. The government mandate and company policy could be potential influences to these statistics. The finding is comparable to other studies reporting BIM adoption rates. For example, the NBS (2017) study found a $62 \%$ adoption rate. The disparities in the level of awareness of BIM application between the two groups, Directors/Managers and professionals, is also evident.

\section{Awareness of 4D Modeling}

As with the emergence of any digital technology, the awareness of $4 \mathrm{D}$ within the industry is a key consideration. Participants were therefore asked to indicate the extent to which they were aware of $4 \mathrm{D}$ modeling applications in the construction sector. The data in Table 6 shows an overall participant awareness of $73.8 \%$. The data indicates that those with director/ management roles are less aware of $4 \mathrm{D}$ modeling applications than those who held professional roles.

\section{Participants' Use of 4D Modeling}

The data displayed in Table 7 shows the participant's use of $4 \mathrm{D}$ in the construction sector. The data shows that overall $31.2 \%$ of the participants had $4 \mathrm{D}$ modeling adopted at their workplace. This suggests a low rate of $4 \mathrm{D}$ implementation in the construction industry. The data also shows that those holding director/management positions are fully aware as to the organization's use of $4 \mathrm{D}$, opposed to $4.1 \%$ of professionals unsure as to if their company uses $4 \mathrm{D}$ software.

\section{Perception of Benefits and Barriers of 4D Modeling}

An analysis of the benefits and barriers to $4 \mathrm{D}$ may highlight reasons for this low rate of adoption. A number of potential benefits of $4 \mathrm{D}$ modeling were identified in the literature. Participants were asked to rate the extent to which these were viewed as benefits of $4 \mathrm{D}$ modeling for construction site health and safety. Figure 1 presents the responses. Both the aggregate scores and disaggregated scores are presented. The disaggregate scores differentiate between directors/managers and professionals and also 4D modeling users and none-users. The participants rated each of the factors on a scale of $1-5$. The results indicate a clear benefit to $4 \mathrm{D}$ being in an increased visualization of the project during the construction process. This factor was scored highest in all four groups with directors/managers who use this software rating this factor a maximum of 5/5. Increased communication with the project team and schedule accuracy also rated highly, with those using $4 \mathrm{D}$ being the highest scoring groups for these factors.

The benefit of $4 \mathrm{D}$ for health and safety management received an average score of $3.13 / 5$ from all groups. Those with director/management roles rated this factor least within the four groups at 2.50/5, signifying a low perception of its benefit for safety management. Those who hold professional roles (both who use $4 \mathrm{D}$ and those who do not) had a higher perception of this benefit, with $3.32 / 5$ scored on by both groups. These responses were however different when compared to a direct question regarding the perception of $4 \mathrm{D}$ as a tool to reduce health and safety risk. Table 8 indicates that both positions responded higher than the use of $4 \mathrm{D}$ for safety management with director/management scoring 3.40/5 and professionals scoring $3.58 / 5$.

Further analysis of the benefits of $4 \mathrm{D}$ with specific regards to safety management identified key areas in which $4 \mathrm{D}$ can positively impact site safety. Participants were asked to rate the use of $4 \mathrm{D}$ to assist key safety management hazards/activities on site. The significance of these activities was derived from current 
TABLE 5 | BIM level 2 adoption.

\begin{tabular}{|c|c|c|c|c|c|c|}
\hline & $\begin{array}{l}\text { Every project is } \\
\text { BIM level } 2(\%)\end{array}$ & $\begin{array}{c}\text { More than } 50 \% \text { of } \\
\text { projects are BIM level } 2(\%)\end{array}$ & $\begin{array}{l}\text { Less than } 50 \% \text { of } \\
\text { projects BIM level } 2(\%)\end{array}$ & $\begin{array}{l}\text { No projects are } \\
\text { BIM level } 2(\%)\end{array}$ & Don’t know (\%) & Total (\%) \\
\hline Director/manager & 0 & 30 & 30 & 35 & 5 & 100 \\
\hline Professional & 7 & 28 & 31 & 21 & 13 & 100 \\
\hline Overall & 5.6 & 28.4 & 30.5 & 23.4 & 12.1 & 100 \\
\hline Adopting BIM level 2 & & 64.5 & & \multicolumn{2}{|c|}{35.5} & 100 \\
\hline
\end{tabular}

TABLE 6 | Awareness of 4D in industry.

\begin{tabular}{llll}
\hline & Not aware of 4D (\%) & Aware of 4D (\%) & Total (\%) \\
\hline Director/manager & 30.0 & 70.0 & 100 \\
Professional & 25.6 & 74.4 & 100 \\
Overall & 26.2 & 73.8 & 100
\end{tabular}

TABLE 7 | Use of 4D in industry.

\begin{tabular}{lllll}
\hline & $\begin{array}{l}\text { Not using } \\
\text { 4D (\%) }\end{array}$ & $\begin{array}{l}\text { Using } \\
\text { 4D (\%) }\end{array}$ & Don't know (\%) & $\begin{array}{l}\text { Total } \\
(\%)\end{array}$ \\
\hline Director/manager & 70.0 & 30.0 & 0 & 100 \\
Professional & 64.5 & 31.4 & 4.1 & 100 \\
Overall & 65.2 & 31.2 & 3.5 & 100 \\
\hline
\end{tabular}

HSE statistics and literature including aspects of the CDM 2015 regulations. The data in Figure 2 indicates that planning site logistics and plant movement where the highest ranked benefits. The professional participants using $4 \mathrm{D}$ also rating these benefits higher than the other groups with a score of 4.18/5, suggesting these to be key practical benefits of the $4 \mathrm{D}$. These areas of health and safety, along with pedestrian segregation also rely heavily on the visual aspects of the project, therefore, implying further support to the benefits of visualization of project sequencing. The data also suggests that those who use $4 \mathrm{D}$ in professional roles have a higher perception overall of the benefits of using $4 \mathrm{D}$ in health and safety planning as those in these roles ranked each factor higher than director/management roles who also use $4 \mathrm{D}$.

With identified benefits in literature, and the British Standards Institution (2018) encouraging this form of planning to support the development for of safe methods of working, this study indicates that $31.2 \%$ of organizations currently use $4 \mathrm{D}$ within their projects. This minority adoption could be due to barriers preventing its widespread implementation as a tool for safety management.

A number of potential barriers were identified in the literature. Participants were asked to rate the extent to which these potential barriers could affect the adoption and use of $4 \mathrm{D}$ for health and safety management at a construction site management level. Figure 3 shows the extent of these key barriers from both director/manager and professional roles, again separated into those who use $4 \mathrm{D}$ and those who do not to allow further comparison of perceptions. The data indicates that directors/managers using $4 \mathrm{D}$ rated cost in training and time to implement the highest barriers to its adoption. The industry culture is also a consistent high ranked barrier, director/managers both using and not using $4 \mathrm{D}$ rated this barrier higher than those in professional roles indicating a cultural attitude is recognized at high levels within organizations as well as operational levels.

All four groups rated "the progress is not needed" as the lowest barrier suggesting that the process is required within construction. This finding demonstrates the need for the use of this digital technology within health and safety management, however, in adoption rate in this study remains low. This, therefore, would suggest that barriers identified must be the reason for this low adoption of a needed process.

\section{DISCUSSION}

This study was carried out to assess the industries readiness to deliver $4 \mathrm{D}$ in light of the recent publication of BIM standard, PAS1192-6:2018, which includes the application of 4D construction sequencing modeling (British Standards Institution, 2018). The inclusion of $4 \mathrm{D}$ within the key BIM framework documentation could spark an increase in the use of $4 \mathrm{D}$ as these standards become further widespread in delivering BIM level 2 projects. It was, therefore, appropriate to investigate and evaluate the perception of construction industry professionals, the benefits and barriers for adoption of 4D modeling for construction site safety management.

The data from this study indicates current adoption of $4 \mathrm{D}$ statistics at $31.2 \%$; this value could be affected by the $73.8 \%$ awareness of $4 \mathrm{D}$ and also key barriers and perceived advantages/limitations highlighted in the literature. The study indicates that those who hold director/management positions have less awareness of $4 \mathrm{D}$. Considering that this is the category that holds more influence on the company strategy and adoption of new processes, it may suggest this could have an effect on the adoption of $4 \mathrm{D}$ within an organization.

The study has highlighted a number of benefits to the use of 4D modeling as documented in literature sources. The participants within this study agreed that the key advantage of $4 \mathrm{D}$ is in visualization. This factor ranked highest in all groups, with an average score among all groups of 4.65 (out of 5). In addition to visualization, the process has been highlighted as an effective tool for communicating aspects of the project and for more effective logistics management during the construction 


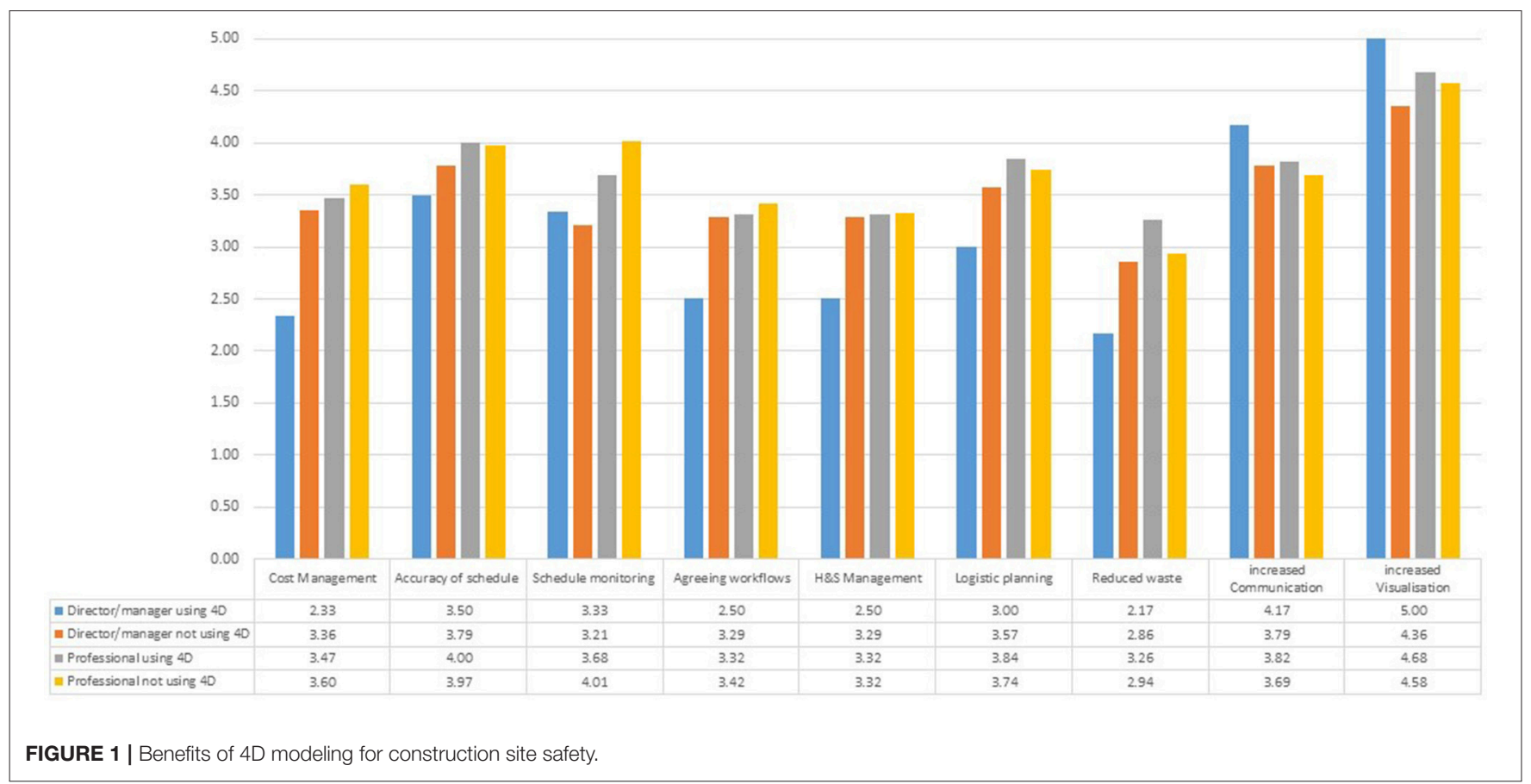

phase. Although these key benefits centered around visualization as opposed to health and safety specifically, the advantage of clear visualization can have natural positive effects on planning for health and safety. This is specifically identified in the planning of logistics including optimum safe plant locations, plant movement and safe access/segregation methodology. The data in this study does, however, suggest that those using $4 \mathrm{D}$ and who hold director/management positions within the organization have a viewed $4 \mathrm{D}$ modeling as being less beneficial when it comes to safety management. Within the study, the director/managers rated " $4 \mathrm{D}$ being beneficial for safety" the least of all groups at 2.5 (out of 5) and they rated the use of $4 \mathrm{D}$ in planning the least in every factor when compared to professionals who also use $4 \mathrm{D}$.

The study has confirmed a number of barriers to the adoption of BIM and 4D for health and safety management, these including cost, time, and culture (including resistance to change). These key barriers follow a common theme within the industry and are similar to those identified, in other literature and influential construction industry reports. The finding of this study indicates that the top-ranked barriers were in the initial outlay/continuous costs of the software/training, time to implement these processes and general industry culture to adopt new techniques and technology. The perception of cost and time as barriers appeared to be higher among directors/managers than professionals. This may suggest that the organization's financial commitment and investment in time to implement such a process and technology across their projects are key issues to overcome.

The cultural barriers have also been highlighted in this study as an underlying factor. This barrier ranked high amongst all groups and featured heavily within literature. This may
TABLE 8 | Perception of 4D as a tool to reduce safety risk.

\begin{tabular}{ll}
\hline Position in organization & $\begin{array}{l}\text { To what extent can 4D be used to } \\
\text { reduce safety risk (Score out of 5) }\end{array}$ \\
\hline Director/manager & 3.40 \\
Professional & 3.58 \\
Overall average & 3.49
\end{tabular}

suggest that resistance to change to new methods of working may be a significant factor to consider when introducing $4 \mathrm{D}$ modeling. It is argued that culture, as discussed by Hardin and McCool (2015) and Egan (1998), can be difficult to change and may not be changed simply by the introduction of new software. It is however important that the construction industry changes its culture as the change would allow the industry to adapt to a collaborative environment and the acceptance of using digital technology to improve health and safety practices.

\section{CONCLUSION AND RECOMMENDATIONS}

The study concludes that the adoption rate of $4 \mathrm{D}$ modeling for construction site safety currently remains low and that the minority of organizations are using 4D. While the PAS 11926 advocates for the wider adoption of BIM for safety, the data suggests that the industry is not yet at a position for this process to be seen as a "standard practice" for safety management. With further understanding and awareness of the benefits of $4 \mathrm{D}$, the industry may break down barriers and further adapt in line with technological advances. While the benefits of $4 \mathrm{D}$ modeling for 

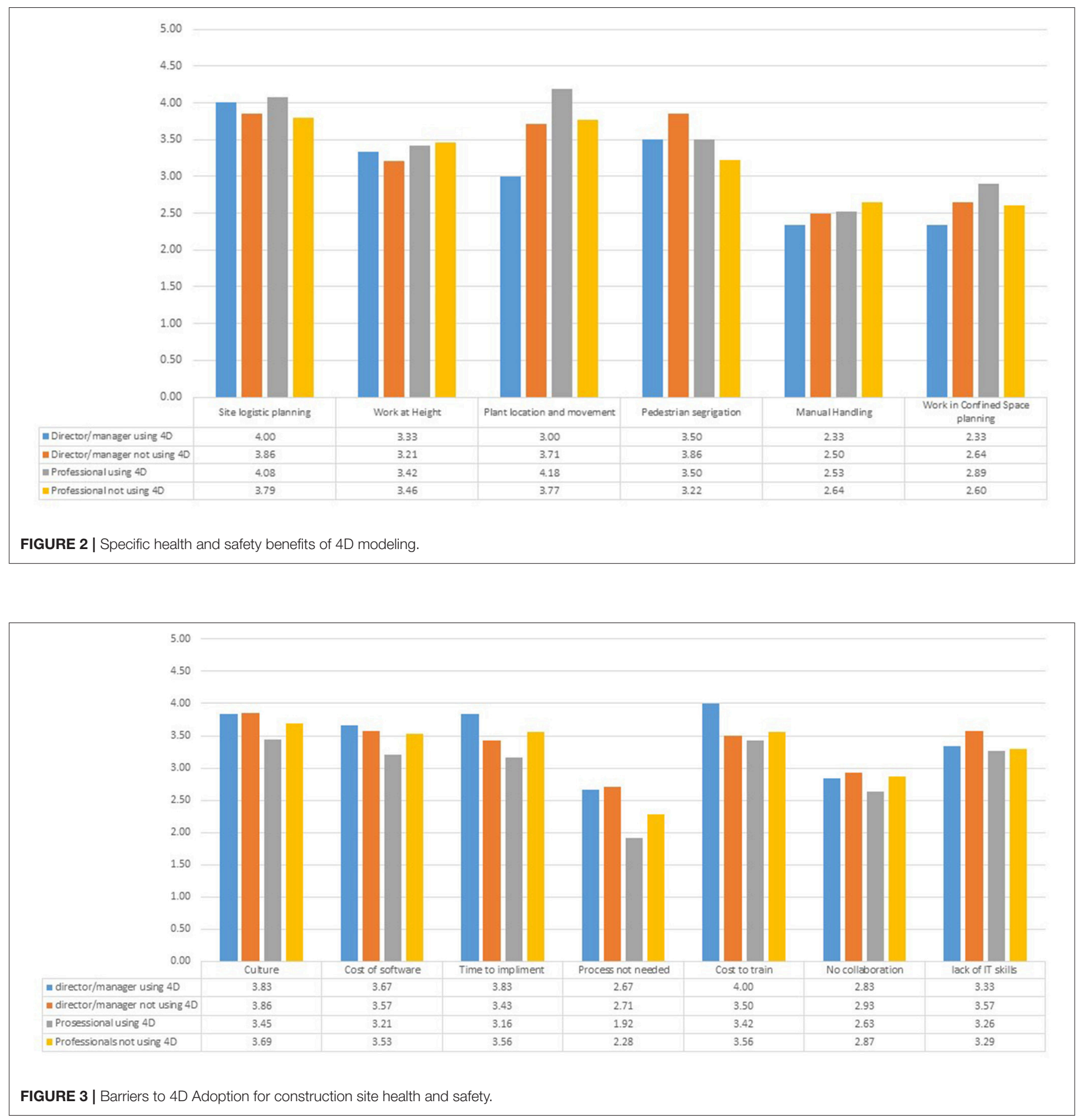

site safety are acknowledged, the findings in this study suggest that technology alone is not the answer. A collaborative approach, understanding of the process, the culture of those involved and indeed the industry itself needs to be in place for this to succeed as a tool to manage health and safety. This may take time and will require these cultural barriers to break before full commitment can be shown.

It is recommended a review of company strategy are undertaken, investigating the feasibility for further investment in 4D modeling within projects. Additional industry training is also recommended in order to increase awareness, in order to understand the current requirements, documentation, available technology and benefits of this process. Further academic research into current and developing adoption of $4 \mathrm{D}$ is recommended, including further quantitative study across the UK to enrich this data. In addition, it is recommended that further studies are conducted in order to provide empirical evidence of the value of $4 \mathrm{D}$ 
modeling in improving site safety practices on construction projects.

\section{ETHICS STATEMENT}

We can confirm that appropriate ethics approval was obtained for this study and that participants to the study were made aware of the purpose and nature of the study. Participants for the questionnaire were advised of the voluntary nature of their

\section{REFERENCES}

Abdulkadir, G., and Godfaurd, J. (2015). Integrating building information and health and safety for onsite construction. Health Saf. Work 6, 39-45. doi: 10.1016/j.shaw.2014.10.002

Ahmed, S., Emam, H., and Farrell, P., Ahmad, O. (eds.). (2014). "Barriers to BIM/4D implementation in Qatar," in Smart, Sustainable and Healthy Cities, Proceeding of the First International Conference of the CIB Middle East and North Africa Research Network (Abu Dhabi: CIB Middle East and North Africa Research Network).

Azhar, S., and Bahringer, A. (2013). "A BIM-based approach for communicating and implementing a construction site safety plan," in Proceedings of the 49th ASC Annual International Conference, 2013 Associated Schools of Construction. (San Luis Obispo, CA).

Azhar, S., Behringer, A., Khalfan, M., Sattineni, A., and Maqsood, T. (2012). "BIM for facilitating construction safety planning and management at jobsite," in Proceeding of the CIB W099 International Conference on "Modelling and Building Health and Safety" (Singapore), 82-92.

Barnes, P., and Davies, N. (2015). BIM in Principle and in Practice, 2nd Edn. London: ICE.

Bernard, H. (2002). Research Methods in Anthropology: Qualitative and Quantitative Approaches, 3rd Edn. Walnut Creek, CA: Alta Mira Press.

British Standards Institution (2018). PAS1192-6:2018 Specification for the Collaborative Sharing and Use of Structured Health and Safety Information Using $B I M$. London: BSI Standards Limited.

Bryman, A., and Bell, E. (2007). Business Research Methods, 3rd Edn. New York, NY: Oxford.

Carson, J. (2018). Can BIM Successfully Deliver Small Construction Projects? Available online at: https://www.thenbs.com/knowledge/can-bimsuccessfully-deliver-small-construction-projects (Accessed November 21, 2018).

Chevin, D. (2018). BIM Level 2 Uptake Still Slow but AR and Automation Up. Construction Manager Insight on BIM, 22-24. Available online at: http://www. constructionmanagermagazine.com/insight/bim-level-2-uptake-still-slow-arand-automation/

Cousins, S. (2016). BIM Spells Safety on Site. Available online at: https://www. healthandsafetyatwork.com/comment/8279 (Accessed February 24, 2018).

Cresswell, J. W., and Plano Clark, V. L. (2011). Designing and Conducting Mixed Method Research, 2nd Edn. Thousand Oaks, CA: Sage.

Dawood, N. (2010). Development of 4D based performance indicators in the construction industry. Eng. Construct. Architect. Manage. 17, 210-230. doi: 10.1108/09699981011024704

Dester, W., and Blockley, D. (1995). Safety-behaviour and culture in construction. Eng. Construct. Architect. Manage. 2, 17-26.

Egan, S. J. (1998). Rethinking Construction the Report of the Construction. Norwich: Construction Taskforce.

Etikan, I., Abubakar, S., and Alkassim, S. (2016). Comparison of convenience sampling and purposive sampling. Am. J. Theoret. Appl. Stat. 5, 1-4. doi: $10.11648 /$ j.ajtas.20160501.11

Eynon, J. (2016). Construction Managers BIM Handbook. Oxford: Wiley Blackwell.

Faridi, A., and El-Sayegh, S. (2007). Significant factors causing delay in the UAE construction industry. Construct. Manage. Econ. 11, 1167-1176. doi: $10.1080 / 01446190600827033$ participation and that by participating, they would be deemed as have consented.

\section{AUTHOR CONTRIBUTIONS}

MS wrote the literature review, gathering of primary data and analysis of data, and conclusions and recommendations. SZ review and supervision. MS and SZ have made significant contribution to the work and approved it for publication.

Fung, I., Tam, V., Lo, T., and Lu, L. (2010). Developing a risk assessment model for construction safety. Int. J. Project Manage. 28, 593-600. doi: 10.1016/j.ijproman.2009.09.006

Gledson, B. (2016). "Exploring the consequences of 4D BIM innovation," in Proceedings 32nd Annual ARCOM Conference, eds P. W. Chan and C. J. Neilson (Manchester: Associaion of Researchers in Construction Management).

Gledson, B., and Greenwood, D. (2016). Surveying the extent and use of 4D BIM in the UK. J. Inform. Technol. Construct. 21, 57-71. Available online at: http:// www.itcon.org/2016/4

Hardin, B., and McCool, D. (2015). BIM and Construction Management Proven Tools, Methods and Workflows, 2nd Edn. Indianapolis, IN: Wiley.

Health and Safety Executive (2015). Managing Health and Safety in Construction, Construction (Design and Management) Regulations 2015.

Health and Safety Executive (2017). Fatal Injuries Arising from Accidents at Work in Great Britain 2017.

Health and Safety Executive (2018). Fatal Injuries Arising from Accidents at Work in Great Britain 2018.

Hughes, P., and Ferrett, Ed. (2016). Introduction to Health and Safety in Construction, 5th Edn. Oxon: Routledge.

Kassem, M., Brogden, T., and Dawood, N. (2012). BIM and 4D planning: a holistic study of the barriers and drivers to widespread adoption. J. Construct. Eng. Project Manage. 5, 1-10. doi: 10.6106/JCEPM.2012.2.4.001

Koo, B., and Fisher, M. (2000). feasibility study of 4D CAD in commercial construction. J. Construct. Eng. Manage. 126, 251-260. doi: 10.1061/(ASCE)0733-9364(2000)126:4(251)

Kumar, B. (2015). A Practical Guide to Adopting BIM in Construction Projects. Dunbeath: Whittles Publishing.

Lacey, J. (2015). The Management of Construction Health and Safety Risk, 4th Edn. Stourbridge: RMS.

Latham, S. M. (1994). Constructing the Team. London: HMSO.

Lingard, H., and Holmes, N. (2010). Understandings of occupational health and safety risk control in small business construction firms: barriers to implementing technological controls. Construct. Manage. Econ. 19, 217-226. doi: 10.1080/01446190010002570

Lingard, H., and Rowlinson, S. (2005). Occupational Health and Safety in Construction Project Management. London: Routledge.

Lymath, A. (2014). The Top Five Barriers to BIM Implementation. NBS. Available online at: https://www.thenbs.com/knowledge/the-top-five-barriers-to-bimimplementation (Accessed March 10, 2018).

Mahalingam, A., Kashyap, R., and Mahajan, C. (2010). An evaluation of the applicability of 4D CAD on construction projects. Automat. Construct. 19, 148-159. doi: 10.1016/j.autcon.2009.11.015

Migilinskasa, D., Popovb, V., Juoceviciusc, V., and Ustinovichiu, L. (2013). "The benefits, obstacles and problems of practical BIM implementation," in Proceedings of the 11th International Conference on Modern Building Materials, Structures and Techniques (Vilnius: Elsevier), 767-774. doi: 10.1016/j.proeng.2013.04.097

Mills, F. (2017). Building a Skyscraper in 4D VR [Online] the B1M. Available online at: https://www.theb1m.com/video/building-a-skyscraper-with-4d-vr (Accessed February 24, 2018).

Mordue, S., and Finch, R. (2014). BIM for Construction Health and Safety. Newcastle: RIBA. 
NBS (2017). National BIM Report 2017. Newcastle upon Tyne: NBS.

Pinto, A., Nunes, I., and Ribeiro, R. (2011). Occupational risk assessment in the construction industry - Overview and reflection. Saf. Sci. 49, 616-624. doi: 10.1016/j.ssci.2011.01.003

Pittard, S., and Sell, P. (2016). BIM and Quantity Surveying. Oxon: Routledge.

RIBA (2015). RIBA Plan of Work 2013 Guide Information Exchanges. Newcastle: RIBA.

Romigh,. A., Kim, J., and Sattineni, A. (2017). "4D scheduling: a visualization tool for construction field operations," in Proceedings of the 53rd ASC Annual International Conference (Seattle, WA: Associated Schools of Construction).

Rwamamara, R., Norberg, H., Olofsson, T., and Lagerqvist, O. (2010). Using visualization technologies for design and planning of a healthy construction workplace. Construct. Innov. 10, 248-266. doi: 10.1108/14714171011060060

Saeedfar, A. (2017). Blog: Role of Safety in BIM. [Online] Assemble Systems. Available online at: https://assemblesystems.com/blog/role-of-safety-in-bim/ (Accessed February 25, 2018).

Smith, N., Merna, T., and Jobling, P. (2009). Managing Risk in Construction Projects, 2nd Edn. Oxford: Blackwell.

Sulankivi, K. (2010). 4D-BIM for Construction Safety Planning. VTT Technical Research Center of Finland.

Tanyer, A., and Aouad, G. (2005). Moving beyond the fourth dimension with an IFC-based single project database. Automat. Construct. 14, 15-32. doi: 10.1016/j.autcon.2004.06.002
Vacharapoom, B., and Sdhabhon, B. (2010). An integrated safety management with construction management using 4D CAD model. Saf. Sci. 48, 395-403. doi: 10.1016/j.ssci.2009.09.009

Zhang, J., and Li, D. (2010). "Research on 4D virtual construction and dynamic management system based on BIM," in Proceeding of the International Conference on Computing in Civil and Building Engineering (Nottingham, UK: Nottingham University Press).

Zhou, W. (2009). An Investigation into a Distributed Virtual Reality Environment for Real-Time Collaborative 4D Construction Planning and Simulation. University of Wolverhampton.

Zhou, Y., Ding, L., and Chen, L. (2013). Application of 4D visualization technology for safety management in metro construction. Automat. Construct. 34, 25-36. doi: 10.1016/j.autcon.2012.10.011

Conflict of Interest Statement: The authors declare that the research was conducted in the absence of any commercial or financial relationships that could be construed as a potential conflict of interest.

Copyright (c) 2019 Swallow and Zulu. This is an open-access article distributed under the terms of the Creative Commons Attribution License (CC BY). The use, distribution or reproduction in other forums is permitted, provided the original author(s) and the copyright owner(s) are credited and that the original publication in this journal is cited, in accordance with accepted academic practice. No use, distribution or reproduction is permitted which does not comply with these terms. 